\title{
Good overall behavioural adjustment in children and adolescents with classic congenital adrenal hyperplasia
}

\author{
Valeria Messina $^{1} \cdot$ Tatja Hirvikoski $^{2,3} \cdot$ Leif Karlsson $^{1} \cdot$ Sophia Vissani $^{4} \cdot$ Lena Wallensteen $^{1} \cdot$ Rita Ortolano ${ }^{4}$ \\ Antonio Balsamo ${ }^{4}$. Anna Nordenström ${ }^{1} \cdot$ Svetlana Lajic $^{1}$
}

Received: 26 December 2019 / Accepted: 24 February 2020 / Published online: 9 March 2020

(c) The Author(s) 2020

\begin{abstract}
Purpose Patients with classic congenital adrenal hyperplasia $(\mathrm{CAH})$ are treated postnatally with life-long glucocorticoid (GC) replacement therapy. Although prolonged exposure to GCs may have a negative impact on behaviour, few studies have studied this issue. We therefore investigated behavioural outcomes in male and female children and adolescents with $\mathrm{CAH}$. Methods An observational study in which Swedish and Italian children and adolescents with CAH identified through neonatal screening for $\mathrm{CAH}$ ( $n=57$, age range 7-17 years) were compared with healthy population controls matched for age and sex ( $n=72$, age range 7-17 years). Thirteen (eight females) of the fifty-seven children and adolescents with CAH had been treated prenatally with dexamethasone (DEX). Standardised questionnaires for parents and self-report scales for children/adolescents were used to assess behavioural and emotional problems, social anxiety, temperament and scholastic competence.

Results There were no statistically significant differences between CAH patients (not prenatally treated with DEX) and controls on most of the scales measuring adaptive functioning or behavioural problems. However, children with $\mathrm{CAH}$ were rated by their parents to have more social problems than controls (Child Behaviour Checklist, CBCL social problems, $p=$ 0.032). In the small group $(n=13)$ of prenatally DEX-treated cases parents rated their children/adolescents to have more mood problems compared with non-DEX-treated children/adolescents with CAH (CBCL-withdrawn/depressed, $p=0.019$ ). Conclusion Children/adolescents with $\mathrm{CAH}$ showed good overall adjustment. The clinical significance of the parentally perceived increase in social problems in children/adolescents with $\mathrm{CAH}$ requires further investigation. The findings underline the importance of psychological support for children/adolescents with a chronic condition.
\end{abstract}

Keywords Behaviour $\cdot$ Cognition $\cdot$ Congenital adrenal hyperplasia $\cdot$ Glucocorticoid $\cdot$ Dexamethasone $\cdot$ Prenatal treatment

Svetlana Lajic
Svetlana.Lajic@ki.se
Department of Women's and Children's Health, Karolinska
Institutet, Pediatric Endocrinology Unit (QB83), Karolinska
University Hospital, SE-17176 Stockholm, Sweden
Department of Women's and Children's Health, Pediatric
Neuropsychiatry Unit, Center for Neurodevelopmental Disorders
at Karolinska Institutet (KIND), Karolinska Institutet, SE-17177
Stockholm, Sweden
Unit for Habilitation \& Health, Stockholm County Council,
Stockholm, Sweden
Department of Medical and Surgical Sciences, S. Orsola-Malpighi
University Hospital, Pediatric Endocrinology Unit, 40138
Bologna, Italy

$\begin{array}{ll}\text { Abbreviations } \\ \text { CAH } & \text { Congenital adrenal hyperplasia } \\ \text { DEX } & \text { Dexamethasone } \\ 21 O H D & \text { 21-Hydroxylase deficiency } \\ \text { GC } & \text { Glucocorticoid } \\ \text { GR } & \text { Glucocorticoid receptor } \\ \text { SW } & \text { Salt-wasting } \\ \text { SV } & \text { Simple virilising } \\ \text { HC } & \text { Hydrocortisone }\end{array}$

\section{Introduction}

Congenital adrenal hyperplasia (CAH) is a group of autosomal recessive disorder. The most common variant, caused by 21-hydroxylase deficiency, occurs in 1:10,000-1:15,000 live births. $\mathrm{CAH}$ is characterised by impaired synthesis of cortisol and aldosterone in the adrenal cortex with a 
consequent increase in adrenal androgens $[1,2]$. In the more severe classic CAH (salt-wasting, SW and simple virilising, $\mathrm{SV}$ ) the increased production of androgens leads to virilisation of external genitalia in affected girls already in utero $[3,4]$.

Neonatal screening programmes for $\mathrm{CAH}$ have been instituted in Sweden and in many other countries worldwide to facilitate early diagnosis and prevent salt-losing crises and death in neonates [5-7]. Consequently, life-long replacement therapy with hydrocortisone (HC) and mineralocorticoid is already started in the second week of life $[1,8]$. However, because of difficulties in mimicking the normal circadian cortisol rhythm with conventional glucocorticoid (GC) treatment, there is a risk of both over- and under-treatment during an individual's lifespan. A dysregulated or flattened rhythm may be related to behavioural changes and mental health symptoms in children during childhood and early adolescence [9-12].

GCs act via the mineralocorticoid receptor and glucocorticoid receptor. These receptors are highly expressed in the prefrontal cortex, which is linked to regions of the brain (e.g. amygdala, hippocampus and cerebellum) involved in emotional behaviour and stress responses [13, 14]. A few studies investigating structural brain differences in adolescents and adult patients with $\mathrm{CAH}$ have reported white matter impairment in the corpus callosum, cerebellum and amygdala, regions that play an important role in emotional regulation. These studies have also reported abnormalities in the hippocampus, a brain region also involved in the regulation of stress and the hypothalamic-pituitary-adrenal axis $[15,16]$. A functional magnetic resonance imaging study of the brain reported altered amygdala function in response to negative stimuli (angry and fearful facial expression) in girls with $\mathrm{CAH}$, suggesting impairments in social cognition that may negatively affect social interactions [17].

Studies on behavioural outcomes in children and adolescents with $\mathrm{CAH}$ are scarce but the few studies that exist have focused on the effects of prenatal androgen exposure on behaviour in girls and women with $\mathrm{CAH}$. Females with $\mathrm{CAH}$ spend more time in male-typical activities in adolescence $[18,19]$. Moreover, they are reported by their mothers to be more aggressive and active than their unaffected sisters [20]. These studies support the view that prenatal androgen exposure has a direct organisational effect on the human brain to determine certain aspects of sex-typed behaviour. The majority of girls with $\mathrm{CAH}$, however, have a female-typical gender identity [21].

In addition, epidemiological studies have shown that girls and women with $\mathrm{CAH}$ [22], but also men with $\mathrm{CAH}$ [23], have substance misuse, mood and anxiety disorders and an increased risk of psychiatric disorders. An increased rate of suicide or suicide attempts has also been reported in men with CAH [24].
Depression [25] and anxiety [26] have been reported in children and adolescents with Cushing's syndrome, a disease characterised by prolonged exposure to elevated levels of GCs [27]. Of note, the incidence of mood-related problems in patients with Cushing's syndrome seems to correlate with the degree and timing of GC exposure [28]. Patients with Cushing's syndrome showed significant improvement in depression and anxiety scores after a reduction of cortisol levels.

Another aspect of the clinical management of $\mathrm{CAH}$ concerns prenatal treatment. Since the mid-1980s, in many medical centres worldwide prenatal treatment of $\mathrm{CAH}$ with dexamethasone (DEX) has been practised to reduce the in utero virilisation in affected girls. Although effective, the treatment is still controversial because of uncertainties regarding its long-term safety [29-31]. In our previous work on a cohort of DEX-treated children and adolescents in the age range of 7-17 years (with and without $\mathrm{CAH}$ ) no differences were found in parent-reported behavioural problems compared with population controls. However, DEXtreated children and adolescents scored themselves as having more social anxiety $[32,33]$. Conversely, we found that healthy children and adolescents treated during the first trimester with DEX were well adjusted [34].

Living with a child with a chronic condition may also affect parenting behaviour and the parent-child relationship, both of which play an important role in the psychological development of the child. Parental overprotection has been related to poor child adjustment and negative health outcomes (decrease in autonomy, depression and anxiety) [35-37]. Studies on women with CAH show that the disease had an influence on their upbringing with a feeling of being overprotected by their parents and that it may affect their schooling because of frequent hospital visits and the inability to attend physical education classes [38].

Thus, the primary purpose of this study was to assess the behavioural outcomes in a cohort of girls and boys with classic $\mathrm{CAH}$ who were diagnosed through national neonatal screening programmes for $\mathrm{CAH}$ in Sweden and Italy. In addition, we sought to determine some behavioural outcomes in a small cohort of children and adolescents with $\mathrm{CAH}$ who were prenatally treated with DEX.

\section{Methods}

\section{Recruitment and participants}

This study is part of a longitudinal study investigating shortand long-term effects of prenatal treatment with DEX in fetuses at risk of $\mathrm{CAH}$ and effects of postnatal chronic GC treatment in patients with CAH (PREDEX study) [31, 34, 39-41]. In this study we include patients from both 
Sweden and Italy. We focus on the behavioural outcome of children and adolescents with classic $\mathrm{CAH}$ and also observe a small group of patients with $\mathrm{CAH}$ who were treated prenatally with DEX (boys during the first trimester and girls during the entire gestational period).

All individuals were initially contacted by letter along with information about the study. All those willing to participate gave their written informed consent to take part in the study. Swedish patients were recruited throughout Sweden to minimise selection bias; healthy controls were enlisted from Stockholm County through the Swedish population registry. All the Swedish participants received reimbursement of 50 euros. Italian patients were recruited from the Emilia-Romagna region and the controls from a group of healthy siblings to patients with $\mathrm{CAH}$. All patients and controls were matched for sex and age. The study was approved by the Regional Ethics Committee in Stockholm and the Ethic Committee of the University of Bologna. The participation rate was $81 \%$ for the CAH cohort and $55 \%$ for the controls.

In total, the CAH cohort comprised 44 children and adolescents with $\mathrm{CAH}$ not prenatally treated with DEX (CAH: 22 boys (seven Italian), 22 girls (five Italian)) and 13 children/adolescents with CAH prenatally treated with DEX (CAH-DEX: five boys and eight girls (two Italian)). The control group included 72 individuals (34 boys (one Italian), 38 girls (one Italian); of these, eight were healthy siblings of five patients with CAH included in the study). All participants were between 7 and 17 years old.

All patients with $\mathrm{CAH}$ were identified through the Swedish or Italian neonatal screening programmes for CAH (30 had SW CAH and 14 SV CAH). Among the patients with $\mathrm{CAH}, 14$ had a null genotype (completely abolished 21-hydroxylase activity). All patients were treated with HC.

Group-specific demographic data are presented in Table 1. Age and parental education did not differ between the CAH, CAH-DEX and control groups. We show length in centimetres $(\mathrm{cm})$ and birth weight in grams (g), adjusted for country of origin. Moreover, length and weight at birth were converted into $z$-scores according to the Swedish and Italian population-based longitudinal reference values [42, 43]. Children and adolescents with $\mathrm{CAH}$ (without prenatal treatment) were longer at birth than population controls $(p=0.022)$; girls treated with DEX during the entire gestational period were born significantly smaller $(p=0.019)$ than CAH girls not treated prenatally (Table 1$)$.

\section{Outcome measures}

The questionnaires were completed by the parents and their children when visiting the clinical psychologists.
Consequently, they had the opportunity to ask for clarification of items, as recommended in the manual [44].

\section{Parent-completed questionnaires}

Data to assess behavioural problems, social phobia and temperament were obtained using three parental ratings: The Child Behaviour Checklist for ages 4-18 years (CBCL/ 4-18), the Social Phobia and Anxiety Inventory for Children-Parent Report (SPAI-C-P) and the Emotionality-Activity-Sociability-Shyness Temperament Survey for children (EAS).

The CBCL/4-18 is an 113-item standardised parental-child instrument for psychiatric screening providing both broadband and narrowband scales. It was used to quantify not only internalising and externalising problems, as well as specific subscales, such as depressive, social and attention problems, but also delinquent and aggressive behaviours [44]. The CBCL total competence score, which measures adaptive functioning, is a sum of scores from three subscales: (1) Activities scale - the number, amount and quality of the child's participation in different leisure activities and everyday tasks; (2) Social scale—participation in social activities, number of close friends and weekly contact with them; and (3) School scale-(e.g. academic performance and need for a special class or support) [44].

The SPAI-C-P is a 26 -item parent-report measure covering cognitive, physiological and behavioural symptoms of social phobia according to the DSM-IV classification system $[45,46]$. The SPAI-C-P includes subscales for 'Public Performance', 'Assertiveness/General Conversation' and 'Traditional Social Encounters'.

Temperament was quantified using the parent-reported EAS with subscales describing four dimensions of temperament: Sociability, Activity, Shyness and Emotionality [47].

\section{Child-completed questionnaires}

The Social Anxiety Scale for Children Revised (SASC-R), a self-reported scale for children, was used to assess children's self-perception of social anxiety and avoidance $[48,49]$. The scale is divided into three subscales: Fear of Negative Evaluation (SASC-FNE) - fear of negative evaluation from peers; Social Avoidance and Distress in new social situations or with unfamiliar peers (SAD-New); and Social Avoidance and Distress in general situations (SADGeneral).

Children and adolescents also estimated their scholastic ability by completing the Scholastic Competence subscale from the Self-Perception Profile for Children [50]. The questionnaire includes school-related items reflecting the children's perception of their competence at school. 


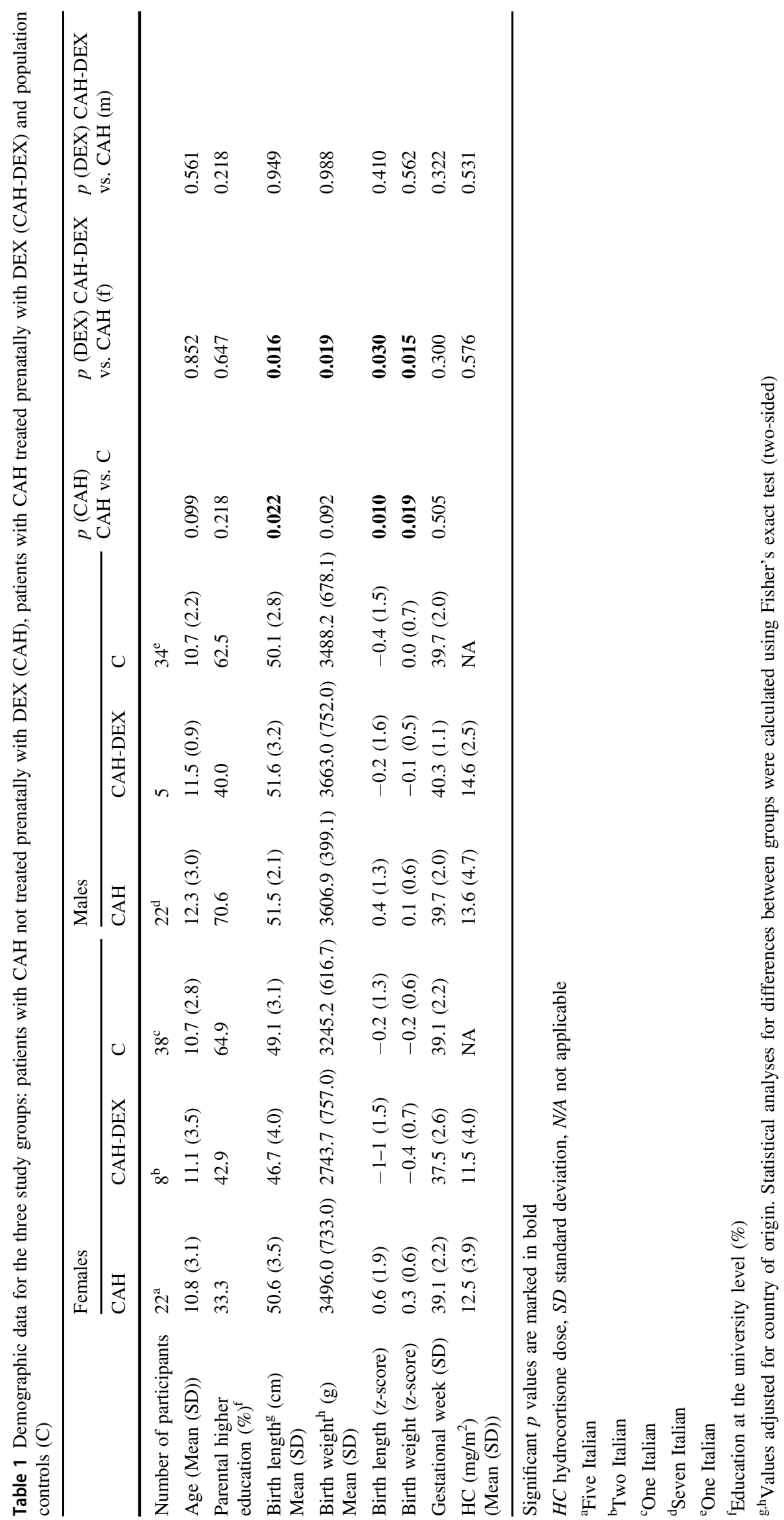




\section{Statistical analysis}

Multiple linear regression analyses were applied to analyse the role of diagnostic status (CAH, CAH-DEX, control), sex, age, parental education and city of origin on behavioural outcomes (dependent variables). The alpha level was set at $p<0.05$. Interactions $(p<0.10)$ between sex and group (CAH, control) were followed up by separate post hoc analyses between patients and controls of the same sex. Effect sizes were calculated using Cohen's $d$ based on group differences adjusted for parental education and country of origin in the linear model. In the model a positive effect size represents higher scores in the CAH cohort and negative values represent higher scores in the controls. Effect sizes were categorised as large $(d \geq 0.80)$, moderate $(d \geq 0.50)$ and small $(d \geq 0.20)$. We did not control for multiple comparisons in order not to miss small, though potentially clinically relevant, effects.

Two multiple regression analyses were performed to determine the effect of genotype (null vs. non-null) and phenotype (SW vs. SV) on social problems within the $\mathrm{CAH}$ group. To investigate which factors contributed to an increased risk of social problems we included sex, age and $\mathrm{GC}$ dose at the time of testing in both of these regression analyses.

Finally, we performed a multiple linear regression analysis to compare behavioural outcomes in children/adolescents with CAH who were prenatally treated with DEX with those with CAH not exposed to DEX in utero. SPSS version 24 (IBM, Armonk, NY, USA) was used for statistical analysis.

\section{Results}

Here, we present adaptive functioning, behavioural and temperamental outcomes for children and adolescents with CAH treated with $\mathrm{HC}$ from birth and the impact of prenatal DEX treatment. Group averages for all completed questionnaires, regression coefficients $(\beta), p$ values for the main effects of CAH, CAH by sex interactions as well as effect sizes are summarised in Table 2; the main effect of DEX, DEX by sex interactions as well as effect sizes are summarised in Table 3.

\section{Parent-completed questionnaires}

There were no significant differences between the groups or a significant interaction between sex and diagnostic status in the parental ratings of children's problems on the scales measuring adaptive functioning (CBCL total competence score). In addition, we found no significant differences in behavioural problems when the CBCL subscales were grouped on the level of two broad groupings (Internalising and Externalising problems). Finally, there were no significant differences between the groups on the Total problem score (all $p s>0.05$, Table 2).

However, the CAH group was significantly different from the controls on the CBCL subscale Social problems $(\beta=0.60, t(105)=2.05, p=0.042, d=0.26) \quad($ Table 2). We also found a significant interaction between $\mathrm{CAH}$ and sex in Social problems $(\beta=-0.85, t(105)=-2.17, p=$ 0.032 ) and the post hoc analyses revealed that girls with $\mathrm{CAH}$ were scored by their parents to have significantly more problems than control girls $(F(1,56)=4.3, p=$ 0.043). In contrast, boys with $\mathrm{CAH}$ did not differ significantly from control boys $(F(1,49)=3.5, p=0.067)$.

The analysis of parental estimations of their children's social anxiety using the three factors of the SPAI-C-P did not reveal any significant differences between the groups.

In the Temperament Survey for children (EAS) none of the four aspects of temperament analysed showed a significant difference between the groups $(p>0.05$, Table 2).

\section{Child-completed questionnaires}

In the children's self-reports of social anxiety, as measured by SASC-R, we did not identify any significant difference between the groups $(p>0.05$, Table 2$)$.

In the comparison of the children and adolescence's ratings on scholastic competence in the Self-Perception Profile for Children there were no significant differences between the groups $(p>0.05$, Table 2$)$.

\section{Effects of prenatal treatment with DEX}

In the parental ratings of children's behavioural problems (CBCL) we found a significant difference between the groups (CAHDEX vs. CAH) for the main effect of DEX on the subscale Withdrawn/Depressed $(\beta=1.10, t(40)=1.90$, $p=0.014, d=0.40)$ and a significant interaction between DEX and $\operatorname{sex}(\beta=-1.41, t(40)=-2.4, p=0.014)$ (Table 3). However, separate post hoc analyses did not reach statistical significance in girls $(F(1,20)=1.3, p=0.266)$ or boys $(F$ $(1,17)=1.7, p=0.210)$.

We also observed a significant interaction between DEX and sex $(\beta=1.43, t(48)=2.55, p=0.015$, Table 3$)$ in the Social problems subscale of the CBCL. The post hoc analyses revealed more social problems in CAHDEX-treated boys compared with boys with $\mathrm{CAH}$ that had not received prenatal DEX therapy $(F(1,17)=11.5, p=0.003)$.

There were no significant differences between the groups in the analysis of parental estimations of their children's social anxiety using the three factors of the SPAI-C-P $(p>$ 0.05 , Table 3). 


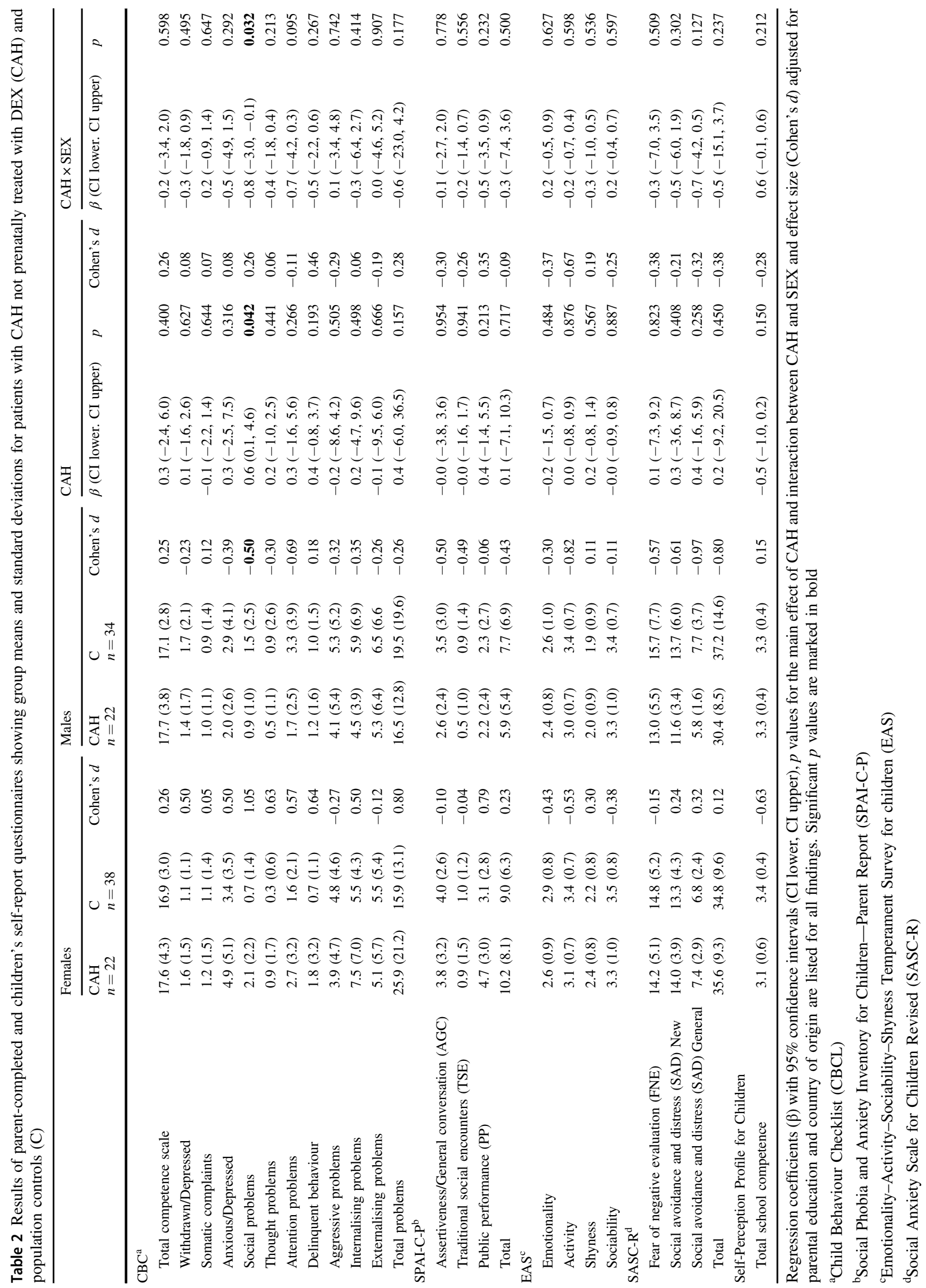




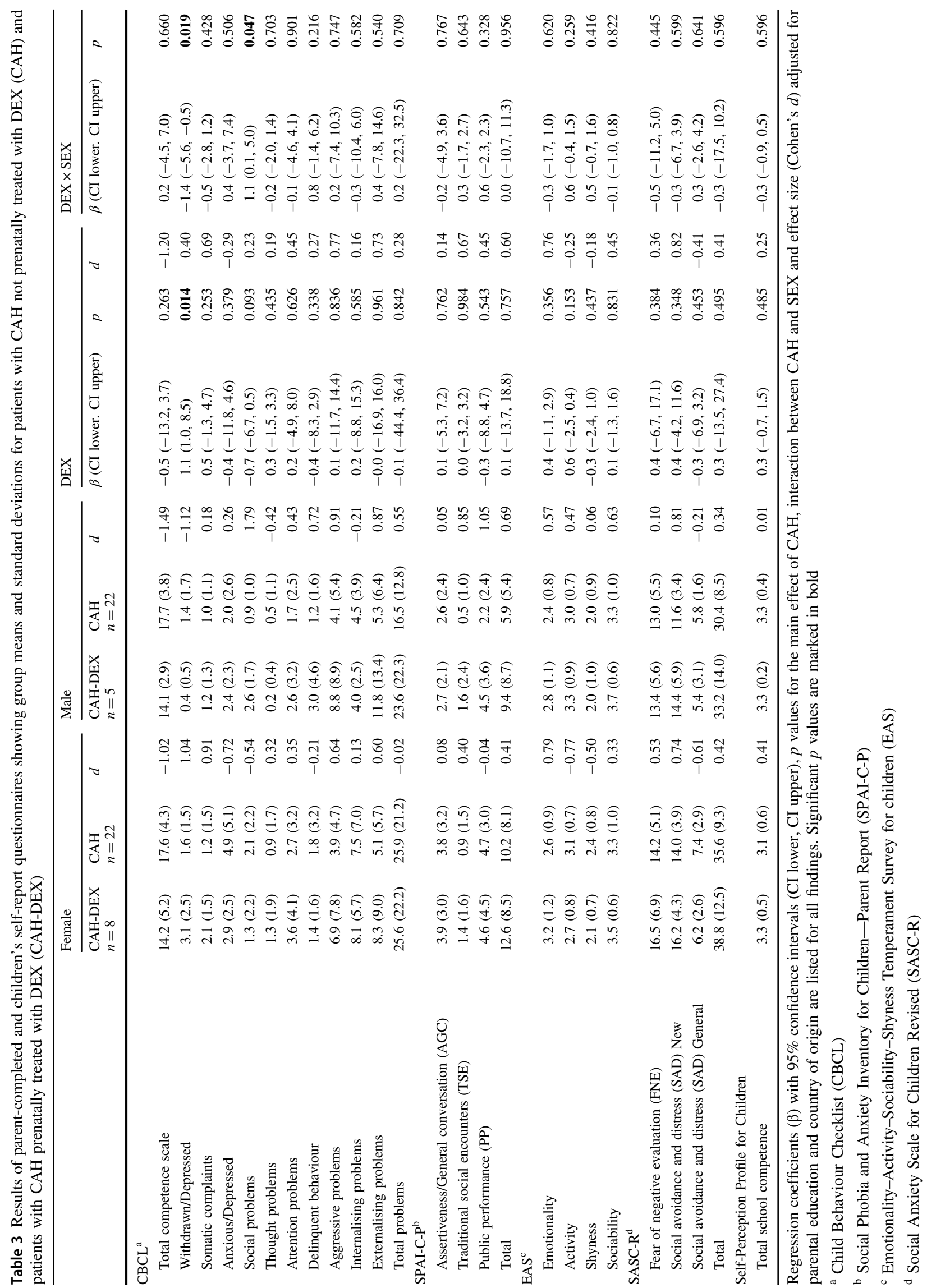


In the Temperament Survey for children (EAS) none of the four aspects of temperament analysed showed a significant difference between the groups $(p>0.05$, Table 3$)$.

There were no significant differences between the groups in the children's self-reports of social anxiety, as measured by SASC-R nor on scholastic competences in the SelfPerception Profile for Children ( $p>0.05$, Table 3$)$.

\section{Social problems regression analyses}

Neither genotype, phenotype nor GC dosage contributed to the prediction $(p>0.5)$.

\section{Discussion}

In the present study we investigated the behavioural outcomes in a group of children and adolescents with $\mathrm{CAH}$ who were diagnosed early via neonatal screening programmes for $\mathrm{CAH}$ in Sweden (nationwide) and Italy (Emilia-Romagna region). We also describe the behavioural outcomes in a small group of children and adolescents with $\mathrm{CAH}$ who were treated prenatally with DEX. To investigate behavioural problems, adaptive functioning and temperament a battery of questionnaires was completed by parents and children and adolescents. The result of a good overall adjustment was expected, as we previously observed normal intelligence, executive functioning, learning and long-term memory in the current Swedish cohort. Indeed, our patient cohort seems to be well adjusted. Such positive adjustment may be attributed in part to close monitoring and access to continuity of care and psychological support.

The only significant group difference in the parental questionnaires was the higher incidence of social problems among $\mathrm{CAH}$ children and adolescents compared with the population controls. Moreover, comparing children and adolescents with $\mathrm{CAH}$ who were prenatally treated with DEX with children and adolescents with CAH who had not received such treatment, our results indicate more withdrawn-depressed problems in DEX-treated children and adolescents and more social problems in DEX-treated boys, as reported by their parents (CBCL).

The CBCL Social problems subscale assesses socially immature behaviours and difficulties in establishing close relationships with peers, as assessed with such items as 'Act too young for his or her age', 'Clings to adults or too dependent' and 'Does not get along with other kids'. Systematic studies focusing on the possible causes of social problems in children with $\mathrm{CAH}$ are scarce. Our results may not be surprising given that it is known that children with a chronic medical condition display less prosocial behaviour with peers [51]. A chronic medical disease may have a negative influence on psychosocial development, especially if promoting positive adaptation is challenging for the parents. Evidence from the literature suggests that the parental emotional state and parenting styles impact the child's developmental trajectory. Parenting an ill child may lead to high parental stress and associated less effective parental strategies [52].

A systematic review found that parental psychological distress in parents of children with Type 1 diabetes mellitus was associated with more problematic behaviour in children [53], although the causal direction of this association is not clear. Thus, our findings underline the importance of screening and the need for counselling and emotional and psychological support for parents with ill children. Finally, further factors associated with social functioning in girls with $\mathrm{CAH}$ may be specific issues, such as body image, sexual functioning and self-stigma.

Of note, studies on behavioural outcome in children with $\mathrm{CAH}$ are scarce and those that are available have mostly focused on sex-specific issues (mainly in females) based on the hypothesised link between androgen effects and behavioural development. Previous studies investigating $\mathrm{CAH}$ in girls reported a higher level of aggression and a preference for masculine, physical sports and behaviours compared with unaffected females $[54,55]$. However, in our cohort we did not observe any difference between girls with $\mathrm{CAH}$ and control girls in the subscale of CBCL assessing aggressive behaviour. Aggressive behaviour was assessed using a subscale of the CBCL questionnaire containing such items as 'Argues a lot', 'Cruelty', 'Bullying or meanness to others' and 'Destroys things belonging to his or her family'.

Some studies have also shown a significant increase in anxiety disorders in boys and girls with $\mathrm{CAH}$ [56]. In our study the children and adolescents with $\mathrm{CAH}$ did not report more social anxiety compared with the control children and adolescents. Likewise, we did not observe any betweengroup differences on the Scholastic Competence subscale for self-rated scholastic competence. Thus, there was good agreement between the parental ratings and the children's and adolescents' self-ratings, indicating a good overall psychological adjustment in children and adolescents with $\mathrm{CAH}$. Medical treatment with $\mathrm{HC}$ and rapid initiation of therapy after neonatal screening may be important factors in helping to maintain psychological well-being.

Our study cohort also included a small number of children and adolescents who had been treated prenatally with DEX. The parents of these children and adolescents reported more social problems in males and more withdrawn/ depressed problems in girls. However, because the analyses of these data were limited by poor statistical power, we were not able to draw any formal conclusions. Consequently, we suggest the use of multi-source assessment in larger studies.

In conclusion, our results on behavioural outcomes in patients with $\mathrm{CAH}$ confirm previous findings of good overall psychological adjustment in boys and girls with 
CAH $[57,58]$. Using parental questionnaires and children's self-reports, we did not identify any major behavioural problems. Our results indicate, however, more social problems in children and adolescents with $\mathrm{CAH}$, as well as possibly more withdrawn-depressed problems in DEX-treated children/adolescents and more social problems in DEX-treated boys, as reported by their parents (CBCL). These findings highlight the importance of follow-up until adult age and screening of mental well-being. Integrating emotional and psychological support into the overall clinical management of $\mathrm{CAH}$ should be an integral part of the care process.

Acknowledgements We thank Katarina Granath and Anton Gezelius for data acquisition. Open access funding provided by Karolinska Institute.

Funding This study was supported by the Marianne and Marcus Wallenberg Foundation, IFCAH/European Society for Pediatric Endocrinology (ESPE), Stockholm County Council (ALF-SLL), Lisa and Johan Grönberg foundation, Stiftelsen Frimurare Barnhuset i Stockholm, Stiftelsen Samariten, Jerringfonden, Sällskapet Barnavård, Stiftelsen Wera Ekström för Pediatrikforskning, Stiftelsen för Barnendokrinologisk Forskning och Utbildning.

\section{Compliance with ethical standards}

Conflict of interest The authors declare that they have no conflict of interest.

Ethical approval All procedures performed in studies involving human participants were in accordance with the ethical standards of the institutional and/or national research committee and with the 1964 Helsinki declaration and its later amendments or comparable ethical standards.

Informed consent Informed consent was obtained from all individual participants included in the study.

Publisher's note Springer Nature remains neutral with regard to jurisdictional claims in published maps and institutional affiliations.

Open Access This article is licensed under a Creative Commons Attribution 4.0 International License, which permits use, sharing, adaptation, distribution and reproduction in any medium or format, as long as you give appropriate credit to the original author(s) and the source, provide a link to the Creative Commons license, and indicate if changes were made. The images or other third party material in this article are included in the article's Creative Commons license, unless indicated otherwise in a credit line to the material. If material is not included in the article's Creative Commons license and your intended use is not permitted by statutory regulation or exceeds the permitted use, you will need to obtain permission directly from the copyright holder. To view a copy of this license, visit http://creativecommons. org/licenses/by/4.0/.

\section{References}

1. P.W. Speiser, W. Arlt, R.J. Auchus, L.S. Baskin, G.S. Conway, D. P. Merke, H.F.L. Meyer-Bahlburg, W.L. Miller, M.H. Murad, S.
E. Oberfield, P.C. White, Congenital adrenal hyperplasia due to steroid 21-hydroxylase deficiency: an Endocrine Society clinical practice guideline. J. Clin. Endocrinol. Metab. 103(11), 4043-4088 (2018). https://doi.org/10.1210/jc.2018-01865

2. D.P. Merke, S.R. Bornstein, Congenital adrenal hyperplasia. Lancet 365(9477), 2125-2136 (2005). https://doi.org/10.1016/ S0140-6736(05)66736-0

3. A. Wedell, Molecular genetics of 21-hydroxylase deficiency. Endocr. Dev. 20, 80-87 (2011). https://doi.org/10.1159/000321223

4. A. Balsamo, L. Baldazzi, S. Menabo, A. Cicognani, Impact of molecular genetics on congenital adrenal hyperplasia management. Sex. Dev. 4(4-5), 233-248 (2010). https://doi.org/10.1159/ 000315959

5. A. Thilén, A. Nordenström, L. Hagenfeldt, U. von Döbeln, C. Guthenberg, A. Larsson, Benefits of neonatal screening for congenital adrenal hyperplasia (21-hydroxylase deficiency) in Sweden. Pediatrics 101, 4 e 11 (1998)

6. B.L. Therrell, Newborn screening for congenital adrenal hyperplasia. Endocrinol. Metab. Clin. North Am. 30(1), 15-30 (2001)

7. A. Balsamo, E. Cacciari, S. Piazzi, A. Cassio, D. Bozza, P. Pirazzoli, F. Zappulla, Congenital adrenal hyperplasia: neonatal mass screening compared with clinical diagnosis only in the EmiliaRomagna region of Italy, 1980-1995. Pediatrics 98(3 Pt 1), 362-367 (1996)

8. F. Baronio, R. Ortolano, S. Menabo, A. Cassio, L. Baldazzi, V. Di Natale, G. Tonti, B. Vestrucci, A. Balsamo, 46,XX DSD due to androgen excess in monogenic disorders of steroidogenesis: genetic, biochemical, and clinical features. Int. J. Mol. Sci. 20(18), (2019). https://doi.org/10.3390/ijms20184605

9. A. Angold, Adolescent depression, cortisol and DHEA. Psychol. Med. 33(4), 573-581 (2003). https://doi.org/10.1017/s003329170300775x

10. S.H. van Goozen, G. Fairchild, H. Snoek, G.T. Harold, The evidence for a neurobiological model of childhood antisocial behavior. Psychol. Bull. 133(1), 149-182 (2007). https://doi.org/10. 1037/0033-2909.133.1.149

11. A.A. Stone, J.E. Schwartz, J. Smyth, C. Kirschbaum, S. Cohen, D. Hellhammer, S. Grossman, Individual differences in the diurnal cycle of salivary free cortisol: a replication of flattened cycles for some individuals. Psychoneuroendocrinology 26(3), 295-306 (2001). https://doi.org/10.1016/s0306-4530(00)00057-3

12. C. Stetler, S.S. Dickerson, G.E. Miller, Uncoupling of social zeitgebers and diurnal cortisol secretion in clinical depression. Psychoneuroendocrinology 29(10), 1250-1259 (2004). https://doi. org/10.1016/j.psyneuen.2004.03.003

13. B. McEwen, H. Chao, R. Spencer, R. Brinton, L. Macisaac, A. Harrelson, Corticosteroid receptors in brain: relationship of receptors to effects in stress and aging. Ann. N. Y. Acad. Sci. 512, 394-401 (1987)

14. A. Colciago, L. Casati, P. Negri-Cesi, F. Celotti, Learning and memory: steroids and epigenetics. J. Steroid Biochem. Mol. Biol. 150, 64-85 (2015). https://doi.org/10.1016/j.jsbmb.2015.02.008

15. R. Bergamaschi, C. Livieri, C. Uggetti, E. Candeloro, M.G. Egitto, A. Pichiecchio, V. Cosi, S. Bastianello, Brain white matter impairment in congenital adrenal hyperplasia. Arch. Neurol. 63 (3), 413-416 (2006). https://doi.org/10.1001/archneur.63.3.413

16. M.F. Mnif, M. Kamoun, F. Mnif, N. Charfi, N. Kallel, N. Rekik, B.B. Naceur, H. Fourati, E. Daoud, Z. Mnif, M.H. Sfar, S. Younes-Mhenni, M.T. Sfar, M. Hachicha, M. Abid, Brain magnetic resonance imaging findings in adult patients with congenital adrenal hyperplasia: increased frequency of white matter impairment and temporal lobe structures dysgenesis. Indian J. Endocrinol. Metab. 17(1), 121-127 (2013). https://doi.org/10.4103/22308210.107833

17. M. Ernst, F.S. Maheu, E. Schroth, J. Hardin, L.G. Golan, J. Cameron, R. Allen, S. Holzer, E. Nelson, D.S. Pine, D.P. Merke, Amygdala function in adolescents with congenital adrenal 
hyperplasia: a model for the study of early steroid abnormalities. Neuropsychologia 45(9), 2104-2113 (2007). https://doi.org/10. 1016/j.neuropsychologia.2007.01.019

18. S.A. Berenbaum, A.M. Beltz, K. Bryk, S. McHale, Gendered peer involvement in girls with congenital adrenal hyperplasia: effects of prenatal androgens, gendered activities, and gender cognitions. Arch. Sex. Behav. 47(4), 915-929 (2018). https://doi.org/10.1007/ s10508-017-1112-4

19. A. Nordenstrom, A. Servin, G. Bohlin, A. Larsson, A. Wedell, Sex-typed toy play behavior correlates with the degree of prenatal androgen exposure assessed by CYP21 genotype in girls with congenital adrenal hyperplasia. J. Clin. Endocrinol. Metab. 87 (11), 5119-5124 (2002). https://doi.org/10.1210/jc.2001-011531

20. V. Pasterski, P. Hindmarsh, M. Geffner, C. Brook, C. Brain, M. Hines, Increased aggression and activity level in 3- to 11-year-old girls with congenital adrenal hyperplasia $(\mathrm{CAH})$. Hormones Behav. 52(3), 368-374 (2007)

21. V. Pasterski, K.J. Zucker, P.C. Hindmarsh, I.A. Hughes, C. Acerini, D. Spencer, S. Neufeld, M. Hines, Increased cross-gender identification independent of gender role behavior in girls with congenital adrenal hyperplasia: results from a standardized assessment of 4- to 11-year-old children. Arch. Sex. Behav. 44(5), 1363-1375 (2015). https://doi.org/10.1007/s10508-014-0385-0

22. H. Engberg, A. Butwicka, A. Nordenstrom, A.L. Hirschberg, H. Falhammar, P. Lichtenstein, A. Nordenskjold, L. Frisen, M. Landen, Congenital adrenal hyperplasia and risk for psychiatric disorders in girls and women born between 1915 and 2010: a total population study. Psychoneuroendocrinology 60, 195-205 (2015). https://doi.org/10.1016/j.psyneuen.2015.06.017

23. H. Falhammar, A. Butwicka, M. Landen, P. Lichtenstein, A. Nordenskjold, A. Nordenstrom, L. Frisen, Increased psychiatric morbidity in men with congenital adrenal hyperplasia due to 21hydroxylase deficiency. J. Clin. Endocrinol. Metab. 99(3), E554-E560 (2014). https://doi.org/10.1210/jc.2013-3707

24. H. Falhammar, L. Frisen, C. Norrby, A.L. Hirschberg, C. Almqvist, A. Nordenskjold, A. Nordenstrom, Increased mortality in patients with congenital adrenal hyperplasia due to 21hydroxylase deficiency. J. Clin. Endocrinol. Metab. 99(12), E2715-E2721 (2014). https://doi.org/10.1210/jc.2014-2957

25. N. Sonino, G.A. Fava, Psychosomatic aspects of Cushing's disease. Psychother. Psychosom. 67(3), 140-146 (1998). https://doi. org $/ 10.1159 / 000012274$

26. P.T. Loosen, B. Chambliss, C.R. DeBold, R. Shelton, D.N. Orth, Psychiatric phenomenology in Cushing's disease. Pharmacopsychiatry 25(4), 192-198 (1992). https://doi.org/10.1055/s2007-1014405

27. D.J. Devoe, W.L. Miller, F.A. Conte, S.L. Kaplan, M.M. Grumbach, S.M. Rosenthal, C.B. Wilson, S.E. Gitelman, Long-term outcome in children and adolescents after transsphenoidal surgery for Cushing's disease. J. Clin. Endocrinol. Metab. 82(10), 3196-3202 (1997). https://doi.org/10.1210/jcem.82.10.4290

28. W.F. Kelly, M.J. Kelly, B. Faragher, A prospective study of psychiatric and psychological aspects of Cushing's syndrome. Clin. Endocrinol. 45(6), 715-720 (1996)

29. S. Lajic, A. Nordenstrom, T. Hirvikoski, Long-term outcome of prenatal treatment of congenital adrenal hyperplasia. Endocr. Dev. 13, 82-98 (2008). https://doi.org/10.1159/000134827

30. W.L. Miller, Fetal endocrine therapy for congenital adrenal hyperplasia should not be done. Best Pract. Res. Clin. Endocrinol. Metab. 29(3), 469-483 (2015). https://doi.org/10.1016/j.beem. 2015.01.005

31. S. Lajic, L. Karlsson, A. Nordenstrom, Prenatal treatment of congenital adrenal hyperplasia: long-term effects of excess glucocorticoid exposure. Horm. Res. Paediatr. 89(5), 362-371 (2018). https://doi.org/10.1159/000485100
32. T. Hirvikoski, A. Nordenstrom, T. Lindholm, F. Lindblad, E.M. Ritzen, A. Wedell, S. Lajic, Cognitive functions in children at risk for congenital adrenal hyperplasia treated prenatally with dexamethasone. J. Clin. Endocrinol. Metab. 92(2), 542-548 (2007)

33. T. Hirvikoski, T. Lindholm, A. Nordenstrom, A.L. Nordstrom, S. Lajic, High self-perceived stress and many stressors, but normal diurnal cortisol rhythm, in adults with ADHD (attention-deficit/ hyperactivity disorder). Hormones Behav. 55(3), 418-424 (2009). S0018-506×(08)00339-5 [pii] https://doi.org/10.1016/j.yhbeh. 2008.12.004

34. L. Wallensteen, L. Karlsson, V. Messina, A. Gezelius, M.T. Sandberg, A. Nordenstrom, T. Hirvikoski, S. Lajic, Evaluation of behavioral problems after prenatal dexamethasone treatment in Swedish children and adolescents at risk of congenital adrenal hyperplasia. Horm. Behav. 98, 219-224 (2018). https://doi.org/10. 1016/j.yhbeh.2017.11.004

35. G.N. Holmbeck, S.Z. Johnson, K.E. Wills, W. McKernon, B. Rose, S. Erklin, T. Kemper, Observed and perceived parental overprotection in relation to psychosocial adjustment in preadolescents with a physical disability: the mediational role of behavioral autonomy. J. Consult Clin. Psychol. 70(1), 96-110 (2002). https://doi.org/10.1037//0022-006×.70.1.96

36. D. Stein, D.E. Williamson, B. Birmaher, D.A. Brent, J. Kaufman, R.E. Dahl, J.M. Perel, N.D. Ryan, Parent-child bonding and family functioning in depressed children and children at high risk and low risk for future depression. J. Am. Acad. Child Adolesc. Psychiatry 39(11), 1387-1395 (2000). https://doi.org/10.1097/ 00004583-200011000-00013

37. M.M. Spada, G. Caselli, C. Manfredi, D. Rebecchi, F. Rovetto, G. M. Ruggiero, A.V. Nikcevic, S. Sassaroli, Parental overprotection and metacognitions as predictors of worry and anxiety. Behav. Cogn. Psychother. 40(3), 287-296 (2012). https://doi.org/10. 1017/S135246581100021X

38. L. Frisen, A. Nordenstrom, H. Falhammar, H. Filipsson, G. Holmdahl, P.O. Janson, M. Thoren, K. Hagenfeldt, A. Moller, A. Nordenskjold, Gender role behavior, sexuality, and psychosocial adaptation in women with congenital adrenal hyperplasia due to CYP21A2 deficiency. J. Clin. Endocrinol. Metab. 94(9), 3432-3439 (2009). https://doi.org/10.1210/jc.2009-0636

39. L. Wallensteen, M. Zimmermann, M. Thomsen Sandberg, A. Gezelius, A. Nordenstrom, T. Hirvikoski, S. Lajic, Sex-dimorphic effects of prenatal treatment with dexamethasone. J. Clin. Endocrinol. Metab. 101(10), 3838-3846 (2016). https://doi.org/10. 1210/jc.2016-1543

40. L. Karlsson, A. Gezelius, A. Nordenstrom, T. Hirvikoski, S. Lajic, Cognitive impairment in adolescents and adults with congenital adrenal hyperplasia. Clin. Endocrinol. 87(6), 651-659 (2017). https://doi.org/10.1111/cen.13441

41. L. Karlsson, A. Nordenstrom, T. Hirvikoski, S. Lajic, Prenatal dexamethasone treatment in the context of at risk CAH pregnancies: long-term behavioral and cognitive outcome. Psychoneuroendocrinology 91, 68-74 (2018). https://doi.org/10.1016/j. psyneuen.2018.02.033

42. K.A. Wikland, Z.C. Luo, A. Niklasson, J. Karlberg, Swedish population-based longitudinal reference values from birth to 18 years of age for height, weight and head circumference. Acta Paediatrica 91(7), 739-754 (2002)

43. E. Bertino, E. Spada, L. Occhi, A. Coscia, F. Giuliani, L. Gagliardi, G. Gilli, G. Bona, C. Fabris, M. De Curtis, S. Milani, Neonatal anthropometric charts: the Italian neonatal study compared with other European studies. J. Pediatr. Gastroenterol. Nutr. 51(3), 353-361 (2010). https://doi.org/10.1097/MPG.0b013e3181da213e

44. T.M. Achenbach. Manual for the Child Behavior Checklist/4-18 and 1991 Profile. (University of Vermont, Department of Psychiatry, Burlington, VT, 1991) 
45. D.C. Beidel, S.M. Turner, T.L. Morris, A new inventory to assess social phobia in children: The Social Phobia and Anxiety Inventory for Children. Psychol. Assess. 7, 73-79 (1995)

46. C.K. Higa, S.N. Fernandez, B.J. Nakamura, B.F. Chorpita, E.L. Daleiden, Parental assessment of childhood social phobia: psychometric properties of the social phobia and anxiety inventory for children-parent report. J. Clin. Child Adolesc. Psychol. 35(4), 590-597 (2006)

47. A.H. Buss, R. Plomin. Temperament: Early Developing Personality Traits. (Lawrence Erlbaum, Hillsdale, NJ, 1984)

48. A.M. La Greca, S.K. Dandes, P. Wick, K. Shaw, W.L. Stone, Development of the Social Anxiety Scale for Children: reliability and concurrent validity. J. Clin. Child Psychol. 17, 84-91 (1988)

49. A.M. La Greca, W.L. Stone, Social Anxiety Scale for Childrenrevised: factor structure and concurrent validity. J. Clin. Child Psychol. 22, 17-27 (1993)

50. S. Harter, The Self-perception Profile for Children: Revision of the Perceived Competence Scale for Children (University of Denver, Colorado, USA, 1985)

51. S.A. Meijer, G. Sinnema, J.O. Bijstra, G.J. Mellenbergh, W.H. Wolters, Social functioning in children with a chronic illness. J. Child Psychol. Psychiatry 41(3), 309-317 (2000)

52. H.L. Williams, L.A. Cullen, J.H. Barlow, The psychological wellbeing and self-efficacy of carers of children with disabilities following attendance on a simple massage training and support programme: a 12-month comparison study of adherers and nonadherers. Complement Ther. Med. 13(2), 107-114 (2005). https:// doi.org/10.1016/j.ctim.2005.03.007

53. R. Whittemore, S. Jaser, A. Chao, M. Jang, M. Grey, Psychological experience of parents of children with type 1 diabetes: a systematic mixed-studies review. Diabetes Educ. 38(4), 562-579 (2012). https://doi.org/10.1177/0145721712445216

54. S.A. Berenbaum, S.M. Resnick, Early androgen effects on aggression in children and adults with congenital adrenal hyperplasia. Psychoneuroendocrinology 22(7), 505-515 (1997)

55. S.A. Berenbaum, Effects of early androgens on sex-typed activities and interests in adolescents with congenital adrenal hyperplasia. Hormones Behav. 35(1), 102-110 (1999)

56. S.C. Mueller, P. Ng, N. Sinaii, E.W. Leschek, L. Green-Golan, C. VanRyzin, M. Ernst, D.P. Merke, Psychiatric characterization of children with genetic causes of hyperandrogenism. Eur. J. Endocrinol. 163(5), 801-810 (2010). https://doi.org/10.1530/EJE-100693

57. S.A. Berenbaum, K. Korman Bryk, S.C. Duck, S.M. Resnick, Psychological adjustment in children and adults with congenital adrenal hyperplasia. J. Pediatrics 144(6), 741-746 (2004)

58. S.A. Berenbaum, K.K. Bryk, S.C. Duck, Normal intelligence in female and male patients with congenital adrenal hyperplasia. Int J. Pediatr. Endocrinol. 2010, 853103 (2010). https://doi.org/10. $1155 / 2010 / 853103$ 